\title{
Optimization of monochlorotriazine $\beta$-cyclodextrin grafting on cotton and assessment of release behavior of essential oils from functionalized fabric
}

\author{
Shelly Khanna and J. N. Chakraborty* ${ }^{*}$
}

${ }^{*}$ Correspondence:

chakrabortyjn@hotmail.com

National Institute

of Technology,

Jalandhar 144011, India

\begin{abstract}
Monochlorotriazinyl $\beta$-cyclodextrin (MCT $\beta$-CD) was employed for the inclusion complexation with oils of cedarwood, clove, eucalyptus and peppermint to assess their release behavior from functionalized cotton. The process of MCT $\beta-C D$ grafting was optimized using response surface methodology with three independent factors including $\mathrm{MCT} \beta-\mathrm{CD}$ concentration, $\mathrm{pH}$ and curing temperature and effect of their second order interactions on dependent variables as \% nitrogen content, \% graft yield, tensile strength and wash durability was examined. The interaction of MCT $\beta-C D$ concentration and $\mathrm{pH}$ had the decisive effect on the investigated dependent variables. FTIR and \% retained nitrogen confirmed the substantial retention of modified host on functionalized cotton after five vigorous wash cycles. ${ }^{1} \mathrm{HNMR}$ characterized the full entrapment of oils within MCT $\beta-C D$ cavity on cotton. All the oils were substantially retained in the inclusion complexes with the MCT $\beta$-CD before and after wash than when present uncomplexed on the treated cotton. Peppermint was the slowest to fade off and cedarwood was rapid in sublimation from the cyclodextrin moieties.
\end{abstract}

Keywords: Monochlorotriazine, Grafting, \% nitrogen content, \% retained nitrogen, Cyclodextrin moieties

\section{Introduction}

The presence of chemical hosts in the form of native $\beta$-cyclodextrin on cotton facilitates the suppression of essential oil's release from the finished surfaces to a greater extent but their adherence to any of the treated substrates is not long lasting as only weak Vanderwaal and Hydrogen interactions prevail between cotton and $\beta$-cyclodextrin. This is due to the non existence of permanent interactions between the substrate and the anchoring host.

A temporary textile finishing of textiles is easily achieved, but is easy to wash off (Nelson 2002). It is evident that $\beta-C D$ cannot form direct covalent bonds with any textile fiber but it is capable of forming only hydrogen bonds with the cellulose based materials. Their lack of durability on textile substrates severely limits their effective use as fabric finishing agents. Instead, the modified monomolecular containers are postulated

(c) The Author(s) 2017. This article is distributed under the terms of the Creative Commons Attribution 4.0 International License (http://creativecommons.org/licenses/by/4.0/), which permits unrestricted use, distribution, and reproduction in any medium, provided you give appropriate credit to the original author(s) and the source, provide a link to the Creative Commons license, and indicate if changes were made. 
to form van der Waal bonds, ionic bonds or even covalent bonds with suitable textile surfaces such as cotton. There is currently an increasing demand for improved reactive $\beta$-CD derivatives with better stability after storage under different conditions and processes without cleavage or the production of toxic or harmful subsidiary products (Wen et al. 2010). Durable finishing is generally achieved by the slow-release method, in which the treated fabrics slowly release the oil molecules for a long duration of time (Halim et al. 2011). Monochlorotriazinyl- $\beta$-cyclodextrin (MCT- $\beta$-CD) is the first reactive cyclodextrin derivative and can be used to permanently bind $\beta-C D$ to cotton with the conventional reactive dyeing method (Bhaskara-Amrit et al. 2011; Bereck 2010). The reactive chlorine atom of triazinyl group of MCT- $\beta$-CD can react with nucleophilic residues such as ${ }^{-} \mathrm{OH}$ to form covalent bonds (Halim et al. 2010; Sricharussin et al. 2009). It can work as a universal anchor for a wide horizon of textile materials as cotton; fabric or yarns (Halim et al. 2011; Boonsod 2007; Cabrales et al. 2012; Hauser and Jianshuo 2000; Peila et al. 2012; Shown and Murthy 2008; Marwa et al. 2013; Sricharussin et al. 2009). Mixed fiber materials like cotton/polyurethane, cotton/polyamide or even silk can be finished with MCT $\beta$-CD in good yields (Bendak et al. 2010; Ibrahim et al. 2007; Bergamasco et al. 2007; Boonsod 2007), cotton/wool, viscose/wool blends, filter papers \& polyester along with its blends (Anitha et al. 2011; Shahba 2008; Popescu et al. 2011). The application of MCT- $\beta$-CD on textiles is influenced by a number of process parameters viz concentration of MCT $\beta-C D$, time of reaction of MCT $\beta-C D$ with the textile substrate, temperature of curing of MCT $\beta-\mathrm{CD}, \mathrm{pH}$ of reaction and presence of moisture in substrate (Moldenhauer and Reuscher 1999; Rehmann et al. 2003). Some studies have been carried out to assess the impact of independent process variables for the fixation of MCT $\beta$-CD on cotton to assess its antimicrobial activity (Halim et al. 2011), polyester and cotton/polyester blends for imparting antistatic property (Halim et al. 2010) and on thin polyester films after their saponification for the activation of the surface (Popescu et al. 2011). But the interactions of the process variables of MCT $\beta$-CD grafting on textile substrate holds incredible importance as physical properties of the treated substrates are immensely affected. Also, the durability of the reactive host is adjudged based upon its adherence on to the textile surfaces for the anchorage of guests as essential oils. But due to lack of scientific and systematic approach for the elucidation of impact of interactive process variables in any of the previous works, present work was carried out for the process optimization of MCT $\beta$-CD grafting on cotton with the exploitation of the key variables. The stability analysis of essential oils for aroma sustained textiles in presence of the reactive host was investigated for characterized inclusion complexes.

\section{Methods}

\section{Materials}

Thoroughly pre-treated plain woven cotton fabric possessing epi (76), ppi (70), warp (42.8 $\mathrm{Ne}^{\mathrm{s}}$ ), weft $\left(38 \mathrm{Ne}^{\mathrm{s}}\right)$ and GSM (136) was used for finishing with four categories of essential oils, viz. clove (CO; Assay-eugenol $\sim 85 \%$ ), cedarwood (CdO; Assay-cedrol $\sim 70 \%$ ), eucalyptus (EO; Assay-cineole $\sim 60 \%$ ) and peppermint (PO; Assay-menthol $\sim 4 \%$ ). All the analytical grade chemicals, viz. $\beta$-cyclodextrin ( $\beta$-CD-M.W.1134.98 and minimum assay 98\%), cyanuric chloride (M.W. 184), sodium carbonate, sodium hydroxide, ethanol, oils and phenolphthalein were supplied by SDFL (Mumbai, India). UV-Vis-210 
spectrophotometer (Lab India analytical UV 3000+), FTIR-spectroscope (Perkin Elmer, US), Elemental Analyzer (EuroVector EA 3000; CSIR-Central Drug Research Institute: Saif, Lucknow, India), Bruker Avance II NMR Spectrometer (Saif, PU, Chandigarh, India), Thermogravemetric analyzer (SDT Q600 V20.9 Build 20; NITRA, Gaziabad, India), Water bath (Laboratory glassware co., Ambala), Electronic pH meter PH-009 (I), Electronic weighing balance (CAS Model MW-11 series), Drying oven (Kaypee Udyog, Ambala, India), Orbital shaker (Bio-Technology Lab, M.D.U Rohtak, India), Padding Mangle (Electronic and Engg. Company), Laundrometer (RBE, Mumbai) and Tensile tester (Globe Tex Industries) were the equipment used to evaluate the physical properties of the functionalized cotton and stability of the inclusion complex on cotton.

\section{Synthesis and characterization of MCT $\beta-C D$}

The synthesis of MCT $\beta$-CD was carried out according to the procedure described previously without any major process modifications with the use of reactants viz. $\beta$-cyclodextrin and cyanuric chloride in presence of alkaline medium (Khanna et al. 2015). FTIR spectroscopy (for micro structural analysis with FTIR-spectroscope), elemental analysis (for compositional analysis with elemental analyser), Thermogravimetric Analysis (TGA with Thermogravimetric Analyzer) and ${ }^{1} H$-NMR spectra (for host- guest investigation with NMR spectrometer) were used for the characterization of MCT $\beta-C D$ powder.

\section{Solubility analysis of MCT $\beta-C D$ in water}

The solubility of MCT $\beta-C D$ was analyzed in water to assess the modification in native $\beta$-CD in terms of its improvement in aqueous solubility.

\section{Optimization of process parameters of MCT $\beta-C D$ application on cotton}

The process optimization of MCT $\beta-C D$ grafting on cotton was carried out by the response surface methodology using $3^{3}$ Box and Behnken factorial design i.e. MCT $\beta$-CD concentration $(60,70,80 \mathrm{gpl})$, Temperature of curing $\left(100,125,150^{\circ} \mathrm{C}\right)$ and $\mathrm{pH}(6$, $8,10)$ as independent variables. Treated cotton was assessed for Graft yield\%, Nitrogen content\% and change in physical properties of treated cotton explicitly tensile strength and wash durability (up to five washes). Statistical analysis was done using Design Expert software version 7.1.2 (State-ease Inc., Minneapolis, USA). The statistical significance of regression co-efficient and model-fit was checked. Model equations for all responses were also determined (Fischer's test).

Graft yield\% (GY) was measured by the analysis of the weight difference of the treated cotton with MCT $\beta$-CD from the untreated one according to Eq. 1. Nitrogen content\% $\left(\mathrm{N}_{2}\right)$ was assessed for the determination of the amount of MCT $\beta$-CD fixed on cotton according to standard Kjeldhl method. Tensile strength was measured according to the ASTM D5034-1995 (strip method) by using digital tensile strength tester. Wash durability was evaluated as follows $-4 \mathrm{~cm} \times 10 \mathrm{~cm}$ strips of MCT $\beta$-CD treated cotton and further, oil treated cotton samples were washed according to ISO 105-C03:1989 with $5 \mathrm{gpl}$ of soap and $3 \mathrm{gpl}$ of $\mathrm{Na}_{2} \mathrm{CO}_{3}$ with a material to liquor ratio of 50:1. The treated samples were then laundered at $60 \pm 2{ }^{\circ} \mathrm{C}$ for $30 \mathrm{~min}$. The washed samples were rinsed with tap water for $10 \mathrm{~min}$ and dried at room temperature after each wash cycle. The durability to 
wash was determined with FTIR and \% retained nitrogen for 5 subsequent washes. Also, the effect of wash treatments on the \% retention of oils on treated fabrics was investigated for 30 vigorous washes.

$$
\begin{aligned}
\text { Graft yield } \%= & \frac{\text { Final weight of treated cotton }- \text { Weight of untreated cotton }}{\text { Weight of untreated cotton }} \\
& \times 100
\end{aligned}
$$

\section{Characterization, application and stability analysis of inclusion complexes of MCT $\beta$-CD-oils on functionalized cotton}

${ }^{1} \mathrm{H}$-NMR was used to characterize the inclusion complexes of MCT $\beta$-CD and essential oils in $\mathrm{D}_{2} \mathrm{O}$ (solvent) at room temperature and all chemical shifts were measured relative to Trimethylsilane (TMS) as reference. The stoichiometry of MCT $\beta$-CD: oils were assumed to be 1:1. The solutions of MCT $\beta$-CD-oils were prepared at $10 \mathrm{mM}$ in free state (without complex) and at $5 \mathrm{mM}: 5 \mathrm{mM}$ (host: guests) for the complex. The precalculated amount of host and guest oils in uncomplexed and complexed states as $1.6 \mathrm{ml}$ oil (free state), $14 \mathrm{~g}$ host (free state) and $0.8 \mathrm{ml}$ oil and $7 \mathrm{~g}$ host (for inclusion complex). Dry mixing technique was used for complexation with magnetic stirring at $4000 \mathrm{rpm}$ for 25 min to achieve a uniform and stable complex of MCT $\beta$-CD and oils. Further, MCT $\beta$-CD functionalized cotton was treated with essential oils at $10 \%$ concentration to achieve a dynamic yet a stable inclusion complex. Fragrance stability of oils on functionalized cotton was investigated by estimation of their release rate after extraction in ethanol solution from treated cotton at stipulated time intervals at respective $\lambda_{\max } \mathrm{CO}$ $(282 \mathrm{~nm}), \mathrm{CdO}(306 \mathrm{~nm}), \mathrm{EO}(270 \mathrm{~nm})$ and PO $(240 \mathrm{~nm})$ according to Eq. 2. The impact of wash down treatments was analyzed by the estimation of \% retained oils on cotton after 30 subsequent wash cycles as mentioned in "Optimization of process parameters of MCT $\beta$-CD application on cotton" section.

Rate of release of oil at stipulated time gap (\%)

$$
=\frac{\text { Conc. at } 0 \mathrm{~h}-\text { Conc. at stipulated time interval }}{\text { Conc. at } 0 \mathrm{~h}} \times 100
$$

\section{Results and discussion}

\section{Synthesis and characterization of MCT $\beta-C D$}

The yield \% of the reaction mechanism between $\beta-C D$ and cyanuric chloride in alkaline medium was satisfactory enough at $63.34 \%$ with the peripheral structure of synthesized MCT $\beta$-CD as depicted in Fig. 1a. The degree of substitution was found to be 0.3 to 0.5 with molecular weight of 1560 . Elemental analysis of MCT $\beta-C D$ powder had shown about $3.7 \% \mathrm{~N}_{2}$ present in MCT $\beta-\mathrm{CD}$, whereas, $0 \%$ was available in native $\beta-C D$; that confirmed the modification of $\beta$-CD with monochlorotriazine group. FTIR revealed the appearance of bands at $2920,2778 \mathrm{~cm}^{-1}$ for the presence of $\mathrm{C}-\mathrm{H}$ bonds in the synthesized MCT- $\beta$-CD. The presence of strong bands at 1753,759 and $1150 \mathrm{~cm}^{-1}$ characterized $\mathrm{C}=\mathrm{N}, \mathrm{C}-\mathrm{Cl}$ and $\mathrm{C}-\mathrm{O}$ groups. Further, the identification of a band at $1018 \mathrm{~cm}^{-1}$ accounted for carbon atoms in cyclic ring. The characteristic bands in the IR- spectra of the MCT- $\beta-C D$ treated cotton were recorded at $2890(\mathrm{C}-\mathrm{H}), 1745(\mathrm{C}=\mathrm{N}$ stretching $)$ and $1157(\mathrm{C}-\mathrm{O})$ in comparison to control. Also, a strong band at $759 \mathrm{~cm}^{-1}(\mathrm{C}-\mathrm{Cl})$ was absent in the IR spectra of MCT- $\beta-C D$ treated cotton that indicated the involvement 


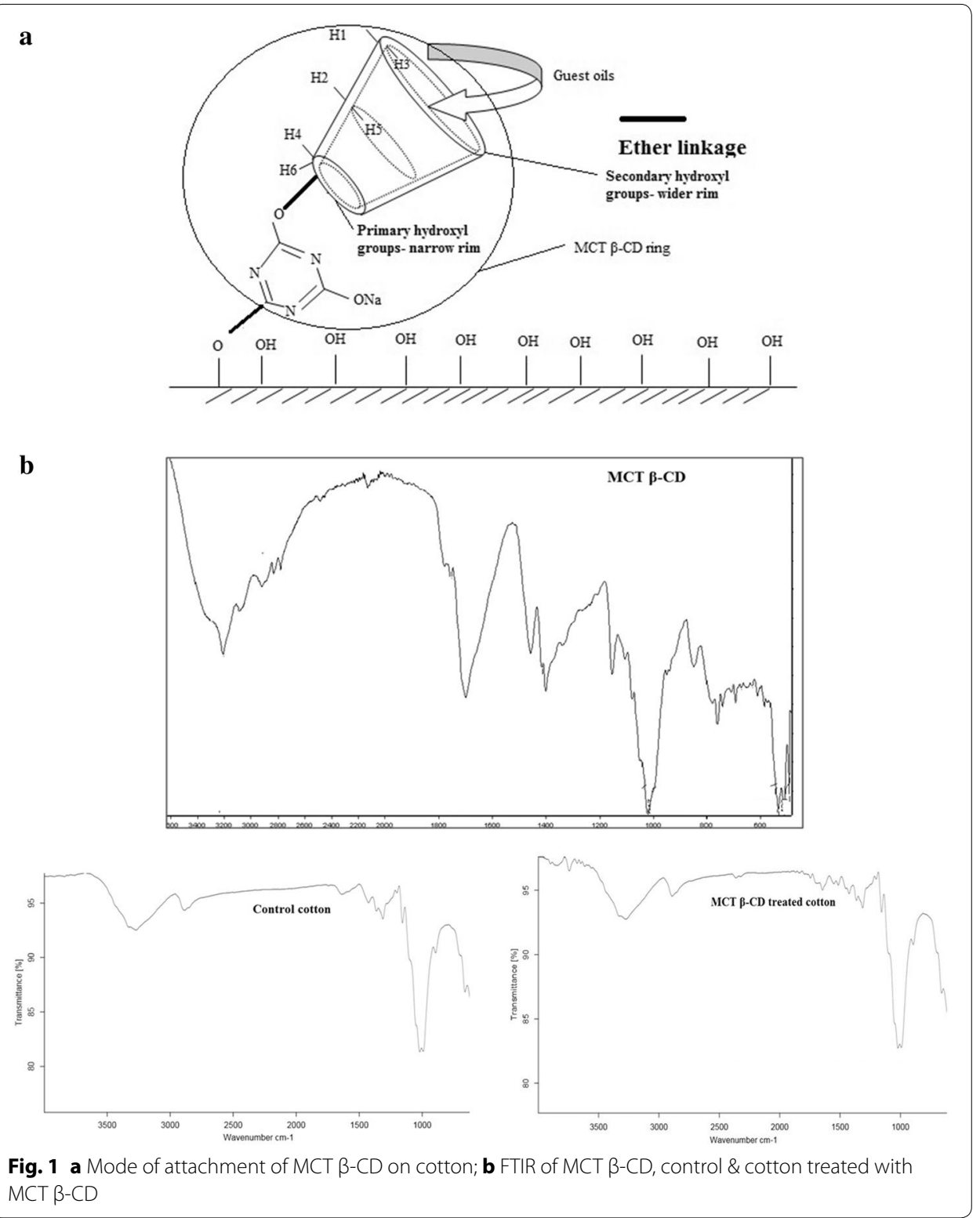

of chlorine atom in the grafting process of MCT- $\beta$-CD on cotton (Fig. 1b) as discussed in an elaborated manner in our previous publication (Khanna et al. 2015). MCT $\beta$-CD had shown thermal decomposition as a measure of \% weight reduction in TGA results (Fig. 2a). At the initial stage, 20\% ( 3.52 mg) weight loss occurred in MCT $\beta$-CD powder as $\mathrm{H}_{2} \mathrm{O}$ molecules are lost at $128^{\circ} \mathrm{C}$, remnant traces of moisture were lost at $195{ }^{\circ} \mathrm{C}$ resulting in about $2.5 \%$ ( $\sim 0.447 \mathrm{mg})$ weight loss. The transition from solid to liquid phase took place at $310{ }^{\circ} \mathrm{C}$ resulting in about $30 \%$ fall in weight and finally, second stage thermal degradation of char resulted in about $27.5 \%$ weight loss at higher temperature of $460{ }^{\circ} \mathrm{C}$. Figure $2 \mathrm{~b}$ depicted ${ }^{1} H$-NMR spectra that characterized MCT $\beta$-CD in terms of respective chemical shifts relative to Trimethylsilane (TMS) as reference in $\mathrm{D}_{2} \mathrm{O}$ as solvent at room temperature The spectra had revealed that the nucleophilic substitution of $\beta-C D$ takes place at the primary hydroxyl groups present at the narrower rim by the 


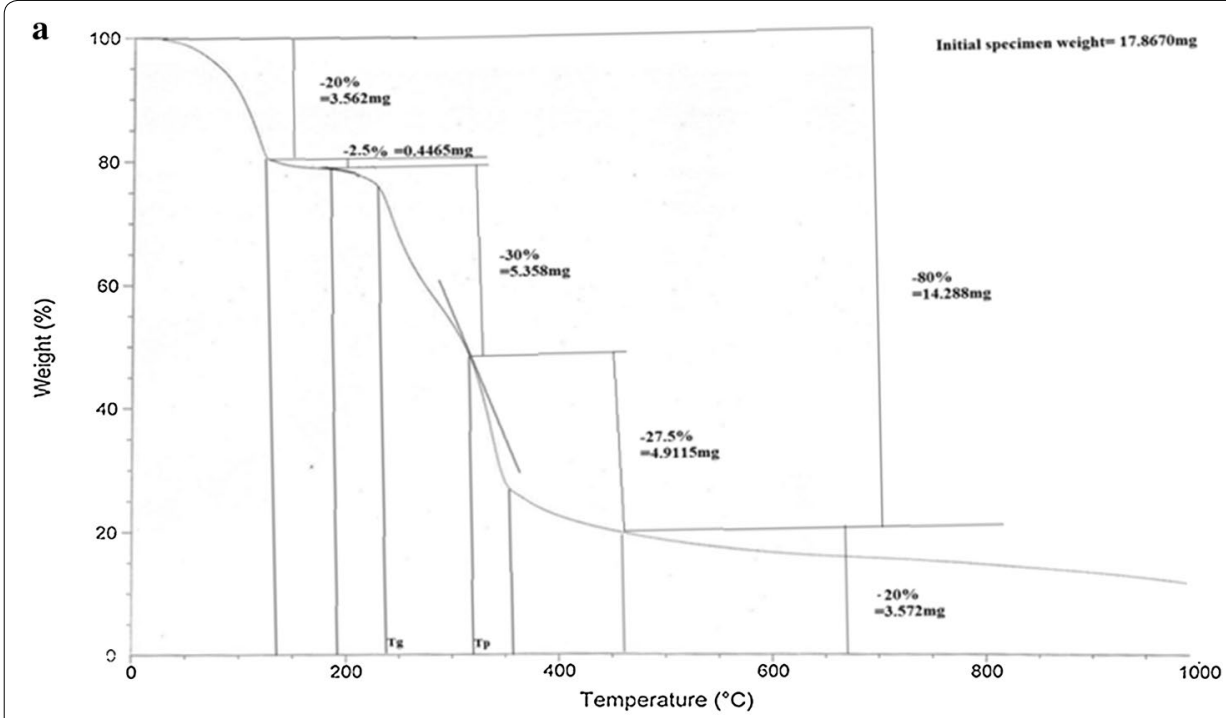

b

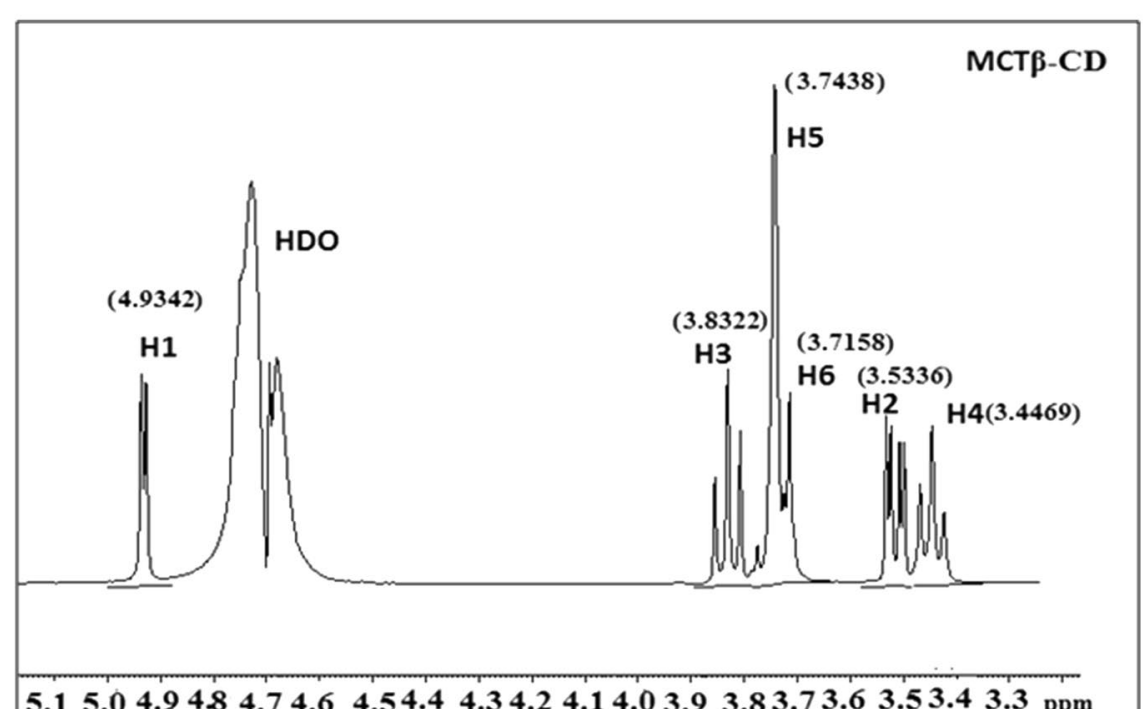

Fig. 2 a TGA of MCT $\beta-C D ; \mathbf{b}^{1} H N M R$ spectra of MCT $\beta-C D$

chlorotriazine moiety (Pessine et al. 2012; Levya et al. 2001; Medronho et al. 2012). The ${ }^{1} \mathrm{H}$-NMR spectra of MCT $\beta$-CD is used as a reference to adjudge the extent of chemical shifts of free and complexed states of the modified host and guests.

\section{Solubility of MCT $\beta-C D$}

MCT $\beta$-CD had shown improved solubility in water as compared to native $\beta-C D$ due to the reduced ring strain of $\beta-C D$ frame. The \% solubility was estimated in the range of $95 \%$ (for $10 \mathrm{gpl}$ ) up to $65 \%$ (for $100 \mathrm{gpl}$ ). The scarce solubility of $\beta$-CD is due the formation of intramolecular hydrogen bonds between the hydroxyl group at carbon atom 2 (C2) and the hydroxyl group at carbon atom 3 (C3) of the adjacent glucose unit on 
the cyclodextrin periphery, that prevents the $\beta$-CD from being soluble in most of the media, whereas, MCT $\beta-\mathrm{CD}$ is produced by the substitution of primary $\mathrm{C} 6-\mathrm{OH}$ groups from the smaller rim of $\beta-C D$ (which are the most susceptible to substitution). Thus, the substitution had helped in the relaxation of the boat-skew structure of unmodified $\beta$-cyclodextrin, and also, the intramolecular $\mathrm{H}$-bond belt is prevented to form, thereby increasing its solubility in water.

\section{Optimization of process parameters for MCT $\beta-C D$ application on cotton}

The desirability function $(\mathrm{DF})=\mathrm{f}\left\{\mathrm{N}_{2}, \mathrm{GY}, \mathrm{TS}\right.$, and WD $\}$ was formulated as:

$\mathrm{N}_{2} \%$ is \% nitrogen targeted to 'maximum, GY\% is \% Graft yield targeted to 'maximum', TS is \% change in Tensile strength targeted to '1.82' (maximum on the +ve scale, experimental data), WD is wash durability in terms of $\%$ retained weight gain after 5 th wash is targeted to 'maximum.' The optimum DF was achieved at 0.912 at the optimized process variables. The overall DF analysis and formulated model equations are shown in Table 1.

\section{Nitrogen content $\left(\mathrm{N}_{2}\right) \%$}

The increase in MCT $\beta$-CD concentration had shown an increase in $\mathrm{N}_{2} \%$ on cotton due to the availability of more MCT $\beta$-CD molecules from the solution for attachment on the substrate. On the other hand, the increase in $\mathrm{pH}$ of $\mathrm{MCT} \beta$-CD solution had resulted in $\mathrm{N}_{2} \%$ increase from 0.179 to $0.56 \%$ at $\mathrm{pH} 6-8$ and then decreased up to $0.263 \%$ at $\mathrm{pH}$ 10. MCT $\beta-C D$ was unstable in acidic pH of 6 and got stabilized at $\mathrm{pH} 8$ (near to neutral), finally got hydrolyzed at $\mathrm{pH} 10$; thereby reducing the extent of $\mathrm{N}_{2} \%$ on cotton. The minimum of $\mathrm{N} 2(0.169 \%)$ was found at $60 \mathrm{gpl}, 8 \mathrm{pH}$ and $100{ }^{\circ} \mathrm{C}$ and maximum of $\mathrm{N}_{2}$ was observed at $70 \mathrm{gpl}, 8 \mathrm{pH}$ and $125^{\circ} \mathrm{C}$. The interaction of concentration and $\mathrm{pH}$ had resulted in the achievement of the highest $\mathrm{N}_{2} \%$ at 70 gpl and $\mathrm{pH} \sim 8$ as shown in Fig. 3a. With the increase in concentration and temperature, $\mathrm{N}_{2} \%$ decreased substantially due to the hydrolysis of chlorotriazine moiety that prevented its fixation on cotton as shown in Fig. 3b, c.

\section{Graft yield (GY)\%}

Graft yield\% is dependent on the concentration of MCT $\beta-\mathrm{CD}$ and $\mathrm{pH}$ as in Fig. 4a. With the increase in concentration and $\mathrm{pH}$ from $(60 \mathrm{gpl}$ and $6 \mathrm{pH})$ to $(80 \mathrm{gpl}$ and 10 $\mathrm{pH}), \mathrm{GY} \%$ had increased from $9.5 \%$ up to $13.43 \%$ due to the favorable conditions for the MCT $\beta$-CD moiety adherence on cotton; higher MCT $\beta$-CD concentration and alkaline $\mathrm{pH} \sim 10$ had facilitated add on $\%$ for cotton but temperature had little or no impact as the interaction of concentration and $\mathrm{pH}$ had the decisive affect on the fixation of MCT $\beta-\mathrm{CD}$ as shown in Fig. 4b, c. The difference in the trends of $\mathrm{N}_{2} \%$ and GY\% was observed, attributed to the reason that $\mathrm{N}_{2} \%$ on substrate is the actual indicator of the MCT $\beta$-CD presence rather, GY\% is an indirect mode. The hydrolysis of chlorotriazine moiety at high temperatures directly indicated lesser adherence of cyclodextrin cavities on cotton via monochlorotriazine bridge, while higher GY\% at higher temperatures could be due to free and unmodified cyclodextrin cavities present in the synthesized MCT $\beta$-CD powder attached superficially on the cotton; mostly susceptible to removal during washing. 


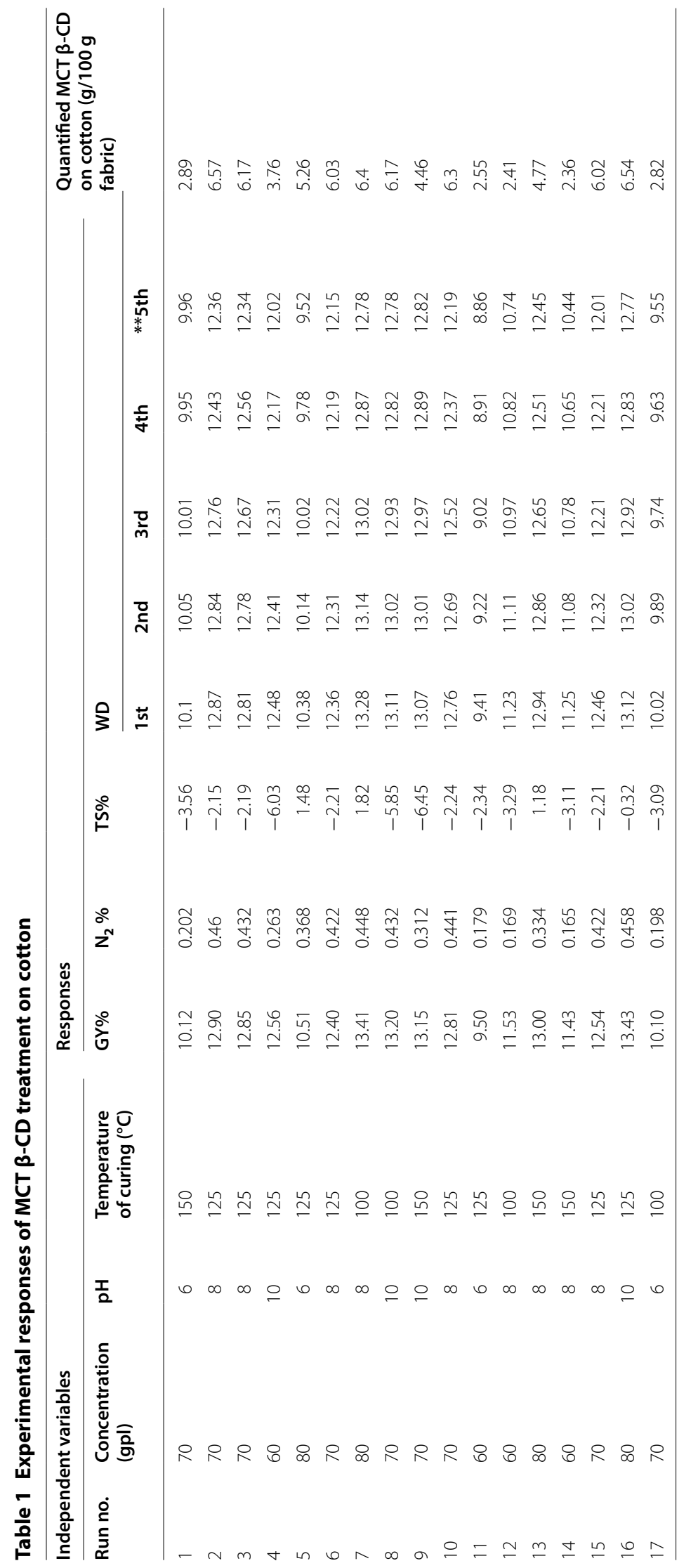




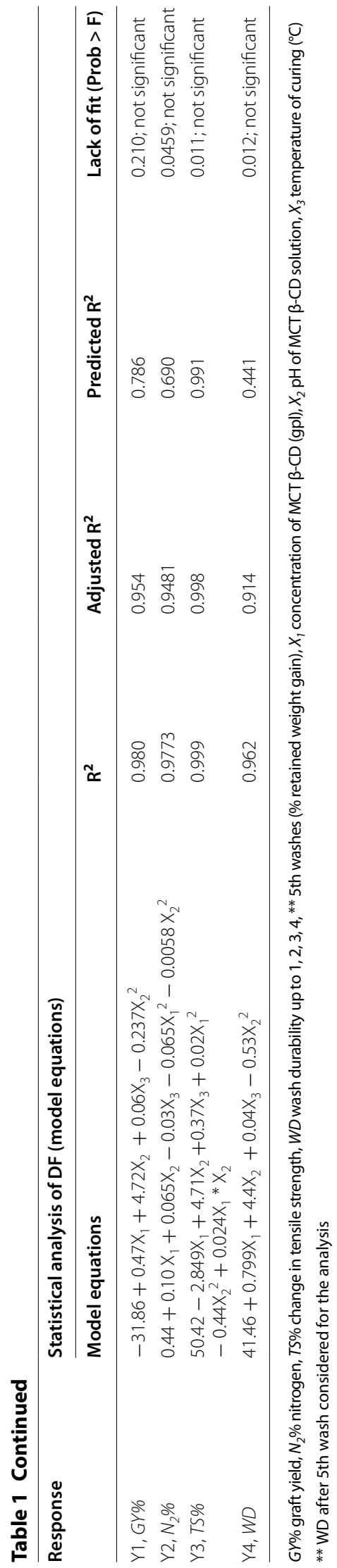




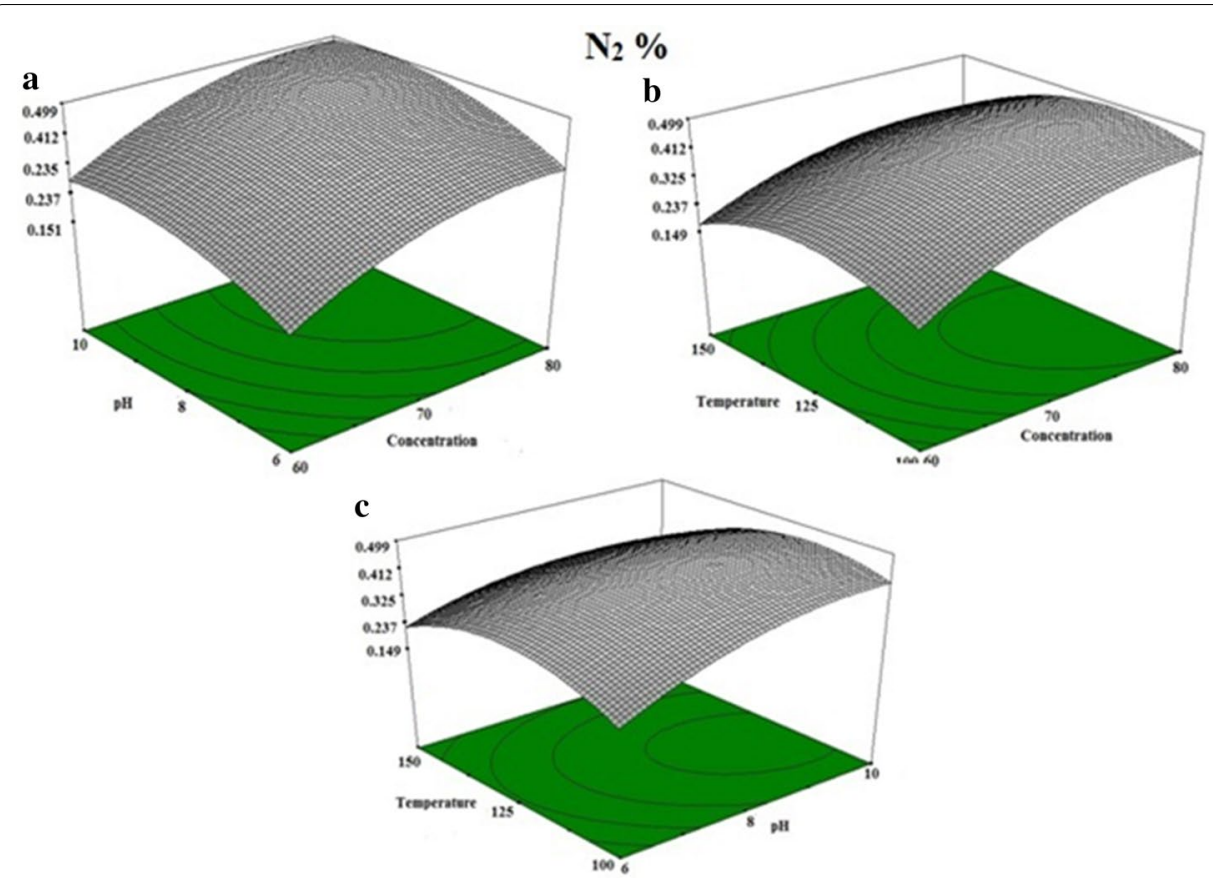

Fig. 3 Effect of $\mathbf{a} \mathrm{pH}$ and concentration, $\mathbf{b}$ temperature and concentration, $\mathbf{c} \mathrm{pH}$ and temperature on $\mathrm{N}_{2} \%$

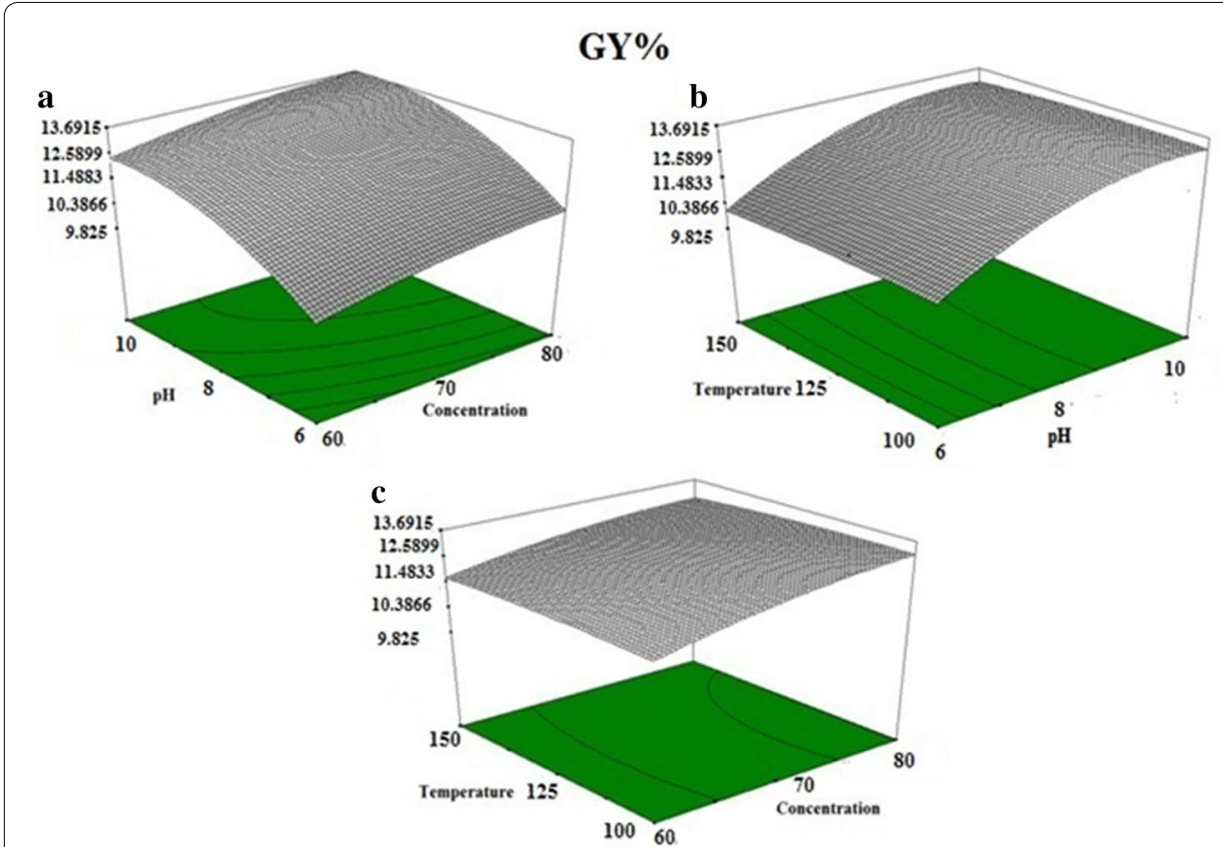

Fig. 4 Effect of $\mathbf{a ~ p H}$ and concentration, $\mathbf{b} \mathrm{pH}$ and temperature, $\mathbf{c}$ temperature and concentration on $\mathrm{GY} \%$

\section{Change in tensile strength (TS)\%}

With the increase in MCT $\beta$-CD concentration from 60 to 80 gpl at pH 6 and $125^{\circ} \mathrm{C}$, the change was from -2.34 to $-3.56 \%$ up to $+1.48 \%$. At $\mathrm{pH} \sim 10$ and $125{ }^{\circ} \mathrm{C}$, TS\% was -6.03 to $-5.85 \%$ up to $-0.32 \%$. This indicated that with the increase in the concentration of MCT $\beta-C D$, less loss is exhibited in TS\%. But with the interaction of $\mathrm{pH}$ with 


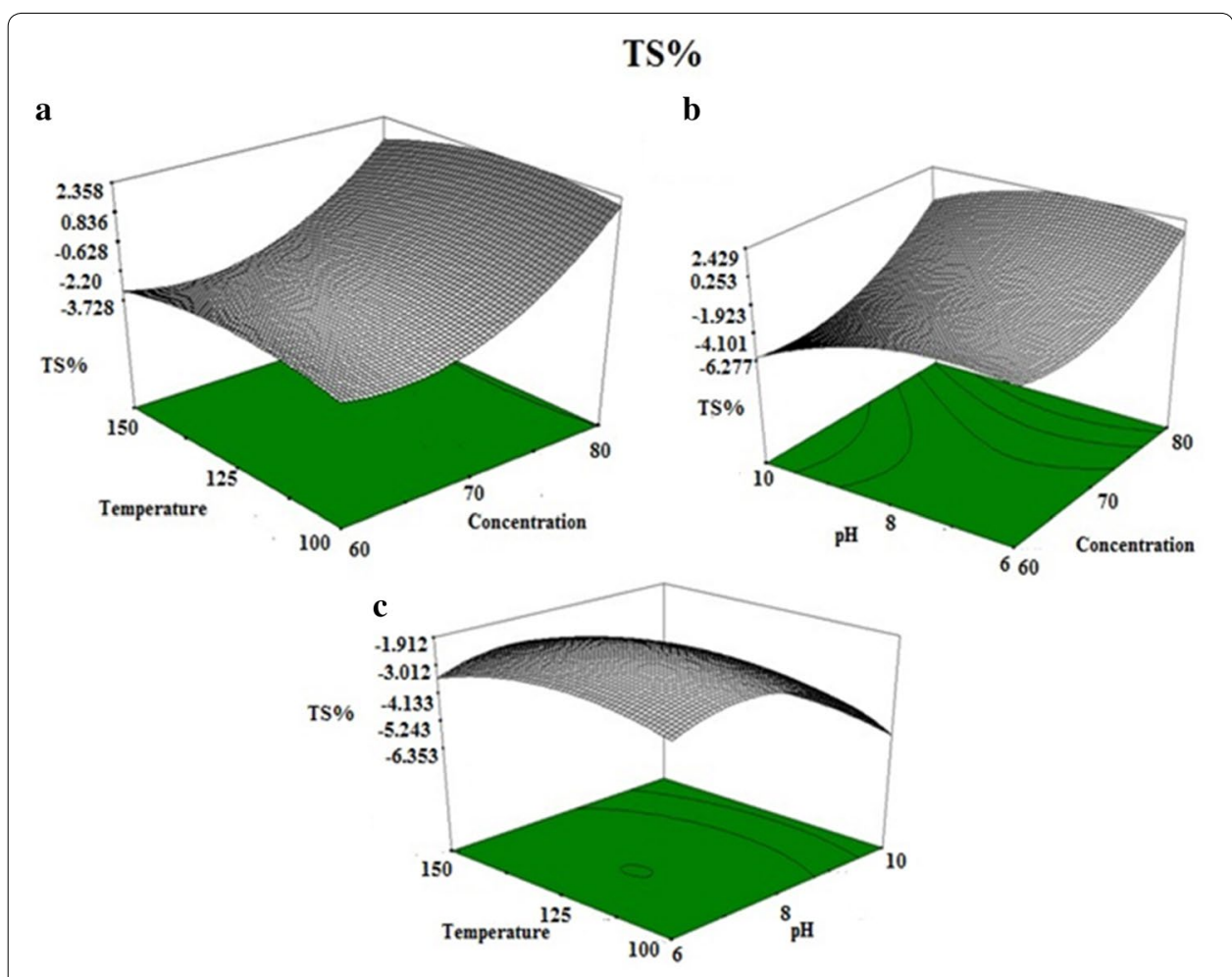

Fig. 5 Effect of a temperature and concentration, $\mathbf{b} \mathrm{pH}$ and concentration, $\mathbf{c} \mathrm{pH}$ and temperature on TS\%

concentration, strength loss was encountered up to $70 \mathrm{gpl}$ followed by an increase at $80 \mathrm{gpl}$; might be due to the plasticizing effect of MCT $\beta-C D$ at higher concentrations that seemed to lessen the restriction of segmental movement of the cellulose chains in the cotton fibre. On the other hand, at $\mathrm{pH} 10$, strength loss reduced from 60 to $80 \mathrm{gpl}$ but the affect of high $\mathrm{pH}$ had overpowered the concentration increase to keep the variable on the negative side as shown in Fig. 5a. Thus, the interaction between $\mathrm{pH}$ and concentration was the main influence behind the strength loss. Degradation of cotton was observed at higher alkaline $\mathrm{pH}$ due to the formation of intermolecular and intramolecular crosslinks that reduces the possibility of equalizing the stress distribution, causing reduction in the capacity to withstand load. Increase in temperature from 100 to $150{ }^{\circ} \mathrm{C}$ at $70 \mathrm{gpl}$ and increasing $\mathrm{pH}(6-10),-3.09$ to $-6.45 \%$ was the observed change (Fig. 5b). The major change was seen at $\mathrm{pH} 10$ with increasing temperature from 100 to $150{ }^{\circ} \mathrm{C}$ $(-5.85$ to $-6.85 \%)$, due to cotton tendering at higher temperatures in presence of alkaline $\mathrm{pH}$ (above $125^{\circ} \mathrm{C}$ ) (Fig. 5c).

\section{Wash durability (WD) as \% retained weight gain}

The highest WD of $12.77 \%$ (with GY\% of 13.43-without wash) at $80 \mathrm{gpl}$ and $\mathrm{pH} \sim 10$ with a minimum of $8.86 \%$ (with GY\% of 9.5 -without wash) was observed at $60 \mathrm{gpl}$ and $\mathrm{pH} \sim 6$. It followed the similar trend as GY\% i.e. with the increase in the levels of both concentration and $\mathrm{pH}, \mathrm{WD}$ was improved as MCT $\beta-\mathrm{CD}$ was affixed in a durable manner and thus, better retention of the host cavities on cotton (Fig. 6 b). Temperature had a little role to play as an independent factor but its interaction with either $\mathrm{pH}$ or concentration, 


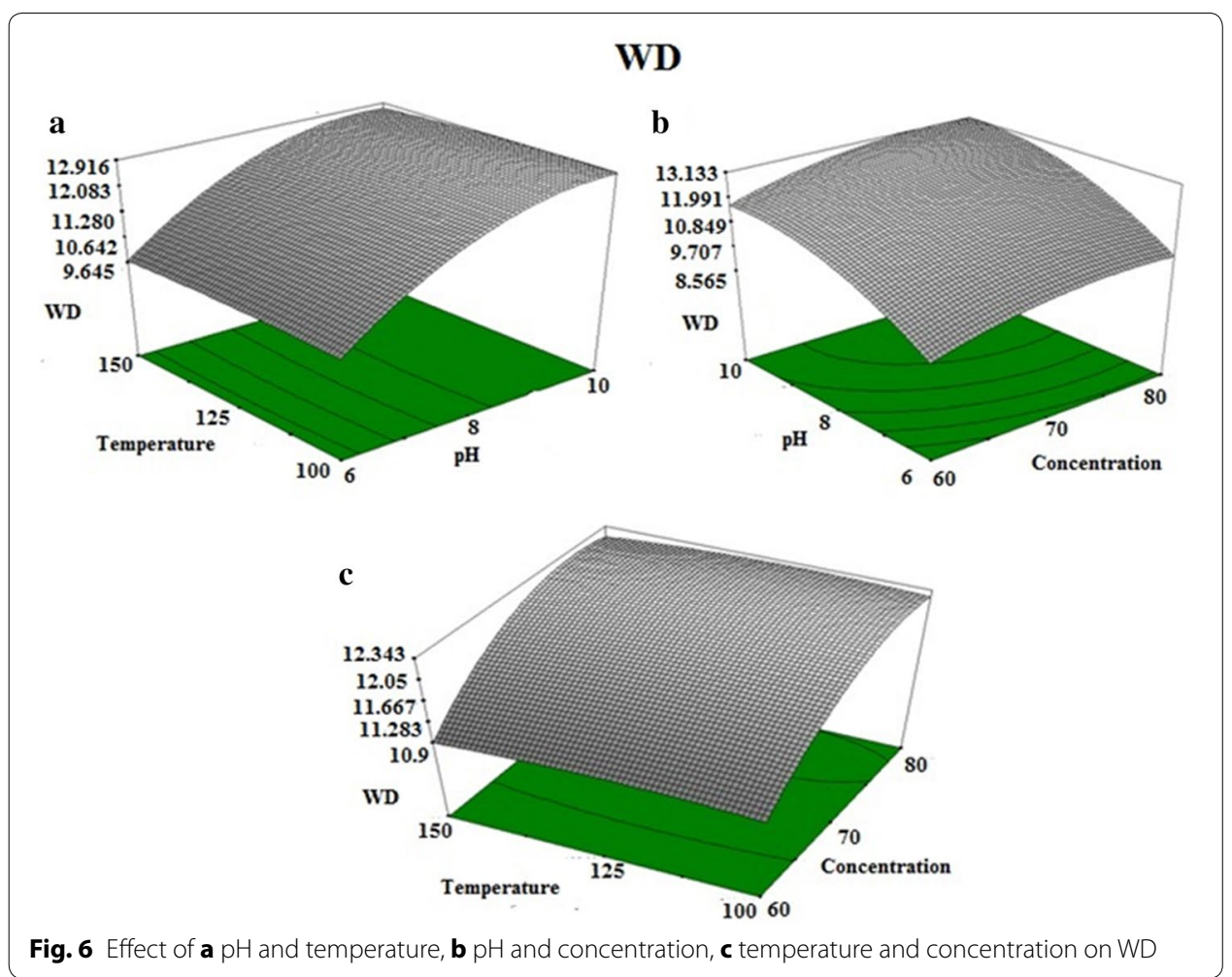

especially at their higher levels of $\left(\mathrm{pH} 10\right.$ and $\left.150{ }^{\circ} \mathrm{C}\right)$ or $\left(80 \mathrm{gpl}\right.$ and $\left.150{ }^{\circ} \mathrm{C}\right)$ had shown a fall in WD due to the intervention of high temperature despite high initial GY\% and superficial deposition of cyclodextrin cavities on cotton; which is further supported by N2\%. Thus, subsequent washing had resulted in the removal of the apparent MCT moieties from the cotton surface at higher temperature (Fig. 6a, c).

The cotton was treated at optimized process variables viz. MCT $\beta$-CD concentration (79.01 gpl), $\mathrm{pH}(7.57)$ and curing temperature $\left(112.37^{\circ} \mathrm{C}\right)$. Then, this functionalized cotton was given 5 subsequent wash down treatments and comparative FTIR was recorded that assured the presence of MCT $\beta$-CD-cellulose grafting intact even after wash treatments as apparent in the unwashed treated cotton at $1157 \mathrm{~cm}^{-1}$ (ether group) as seen in Fig. 7. Residual $\% \mathrm{~N}_{2}$ was analyzed for functionalized cotton (with and without wash) as -0.489 (Without wash), 0.252 (Ist wash), 0.235 (2nd wash), 0.205 (3rd wash), 0.201 (4th wash) and 0.2 (5th wash) that evinced the presence of the reactive host even after washing of cotton. This also ascribed the initial $\% \mathrm{~N}_{2}$ loss during first two washes was due to the inadequate cross linking of MCT $\beta-\mathrm{CD}$ with cotton resulting in washing off MCT $\beta$-CD but with further washes, the $\%$ retained $\mathrm{N}_{2}$ content had stabilized.

\section{Inclusion complexation of MCT $\beta$-CD and oils on cotton}

${ }^{1} \mathrm{H}$-NMR was consummated for inclusion complexation analysis of MCT $\beta$-CD-oils on cotton (Table 2; Figs. 8, 9). The chemical ' $\delta$ ' and induced chemical shifts ' $\Delta \delta$ ' of the MCT $\beta-C D$ and oils in free as well as in compounded state had revealed evident shifts ensuring the formation of dynamic complexes between anchor and guests. $\Delta \delta(\mathrm{H} 5>\mathrm{H} 3)$ had revealed significant entrapment of oil molecules into the cavities for both oils confirming 


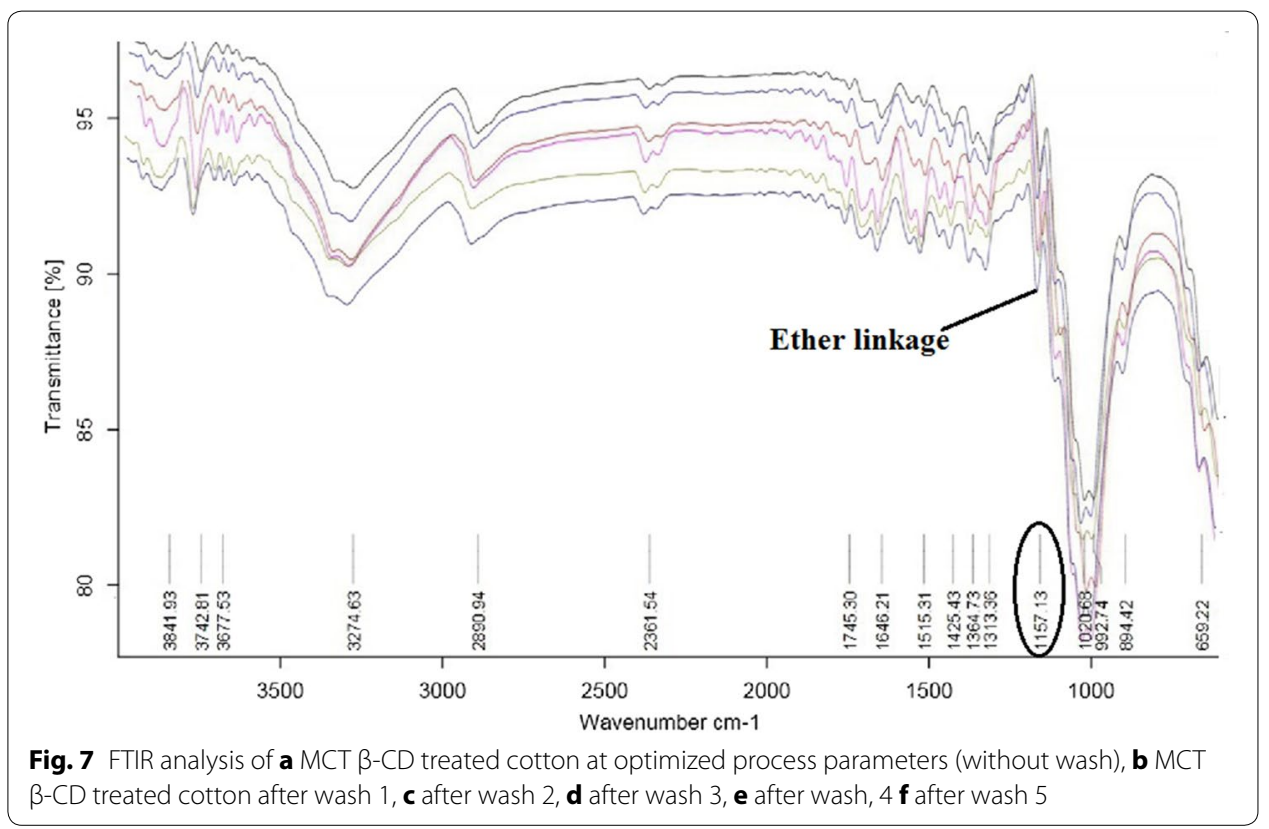

Table 2 Induced shift analysis of MCT $\beta$-CD-oil complexes in free and complex states

\begin{tabular}{|c|c|c|c|c|c|c|c|c|}
\hline $\begin{array}{l}\text { Proton } \\
\text { (MCT } \\
\beta-C D)\end{array}$ & $\delta_{\mathrm{MCT} \beta-\mathrm{CD} \text { (free) }}^{1}$ & $\delta *_{\text {MCT } \beta-C D}^{2}$ (complex) & $\Delta \delta_{\mathrm{MCT} \beta-\mathrm{CD}}^{3}$ & $\delta_{\text {oil (free) }}^{4}$ & $\delta *_{\text {oil (complex) }}^{5}$ & $\Delta \delta_{\text {oil }}^{6}$ & $\begin{array}{l}\text { Pro- } \\
\text { ton } \\
\text { (oil) }\end{array}$ & $\begin{array}{l}\text { Oil } \\
\text { type }\end{array}$ \\
\hline H3 & 3.8322 & 3.7398 & 0.3446 & 3.2453 & 2.321 & 0.9243 & $\mathrm{H}_{\mathrm{g}}$ & \\
\hline \multirow[t]{2}{*}{ H5 } & 3.7438 & 3.4124 & 0.3034 & 5.8937 & 5.131 & 0.7627 & $H_{h}$ & $\mathrm{CO}$ \\
\hline & & & & 5.0256 & 4.823 & 0.2026 & $\mathrm{H}_{\mathrm{i}}$ & \\
\hline $\mathrm{H} 3$ & 3.8322 & 4.659 & -0.8268 & 1.5895 & 1.5123 & 0.0772 & $\mathrm{H}_{\mathrm{i}}$ & \\
\hline H5 & 3.7438 & 4.269 & -0.5252 & 1.3601 & 1.2966 & 0.0635 & $H_{j}$ & $\mathrm{CdO}$ \\
\hline $\mathrm{H} 3$ & 3.8322 & 3.4873 & 0.3446 & 1.5592 & 1.2602 & 0.299 & $H_{d}$ & \\
\hline H5 & 3.7438 & 3.1758 & 0.5681 & 1.6295 & 1.3390 & 0.286 & $\mathrm{H}_{\mathrm{e}}$ & EO \\
\hline $\mathrm{H} 3$ & 3.8322 & 3.54 & 0.2922 & 0.7989 & 0.7357 & 0.0632 & $\mathrm{H}_{\mathrm{a}}$ & \\
\hline H5 & 3.7438 & 3.3644 & 0.3794 & 1.6755 & 1.5584 & 0.1171 & $\mathrm{H}_{\mathrm{g}}$ & $\mathrm{PO}$ \\
\hline
\end{tabular}

$\delta_{\mathrm{MCT} \beta-\mathrm{CD} \text { (free) }}^{1}$ chemical shift of MCT $\beta-\mathrm{CD}$ in free state; $\delta *_{\mathrm{MCT} \beta-\mathrm{CD} \text { (complex)' }}^{2}$ chemical shift of MCT $\beta$-CD in complex with oils; $\Delta \delta_{\mathrm{MCT} \beta-\mathrm{CD}}^{3}$ induced shift of MCT $\beta-C D\left(\delta_{\mathrm{MCT} \beta-\mathrm{CD}(\text { free })}^{1}-\delta_{\text {Complex }}^{* 2}\right) ; \delta_{\text {oil (free) }}^{4}$ chemical shift of oils in free state; $\delta *_{\text {oil (complex)' }}^{5}$ chemical shift of oils in complex with MCT $\beta-C D ; \Delta \delta_{\text {oil }}^{6}$ induced shift of oils $\left(\delta_{\text {oil free }}^{4}-\delta_{\text {oil }}^{* 5}\right)$

the full inclusion of oils into the MCT $\beta-\mathrm{CD}$ cavity as $\mathrm{H} 5$ is more deeply embedded into MCT $\beta$-CD cavity than H3. ${ }^{1} \mathrm{H}-\mathrm{NMR}$ spectra had shown generation of no newer peaks for any oil as complex formation was a dynamic process, the included oils being in a faster exchange between the free and bound states. The $\Delta \delta$ for oils had shown that in EO, Hk, Hd and He protons had shown more induced shifts than the other protons. This could be an indication that the oil had entered from the tail side into the cavity. Similarly, $\mathrm{Hd}$ and $\mathrm{Hg}$ for $\mathrm{PO}$ showed the inclusion of oil from the bottom side; $\mathrm{Hi}$ and $\mathrm{Hj}$ for $\mathrm{CdO}$ depicted segmental inclusion of the oil into the cavity and CO had shown the induced shift pattern as either $\mathrm{Hk}$ or $\mathrm{Hg}$, $\mathrm{Hh}$ and $\mathrm{Hi}$ sided penetration into the cavity as shown in Fig. 10. 

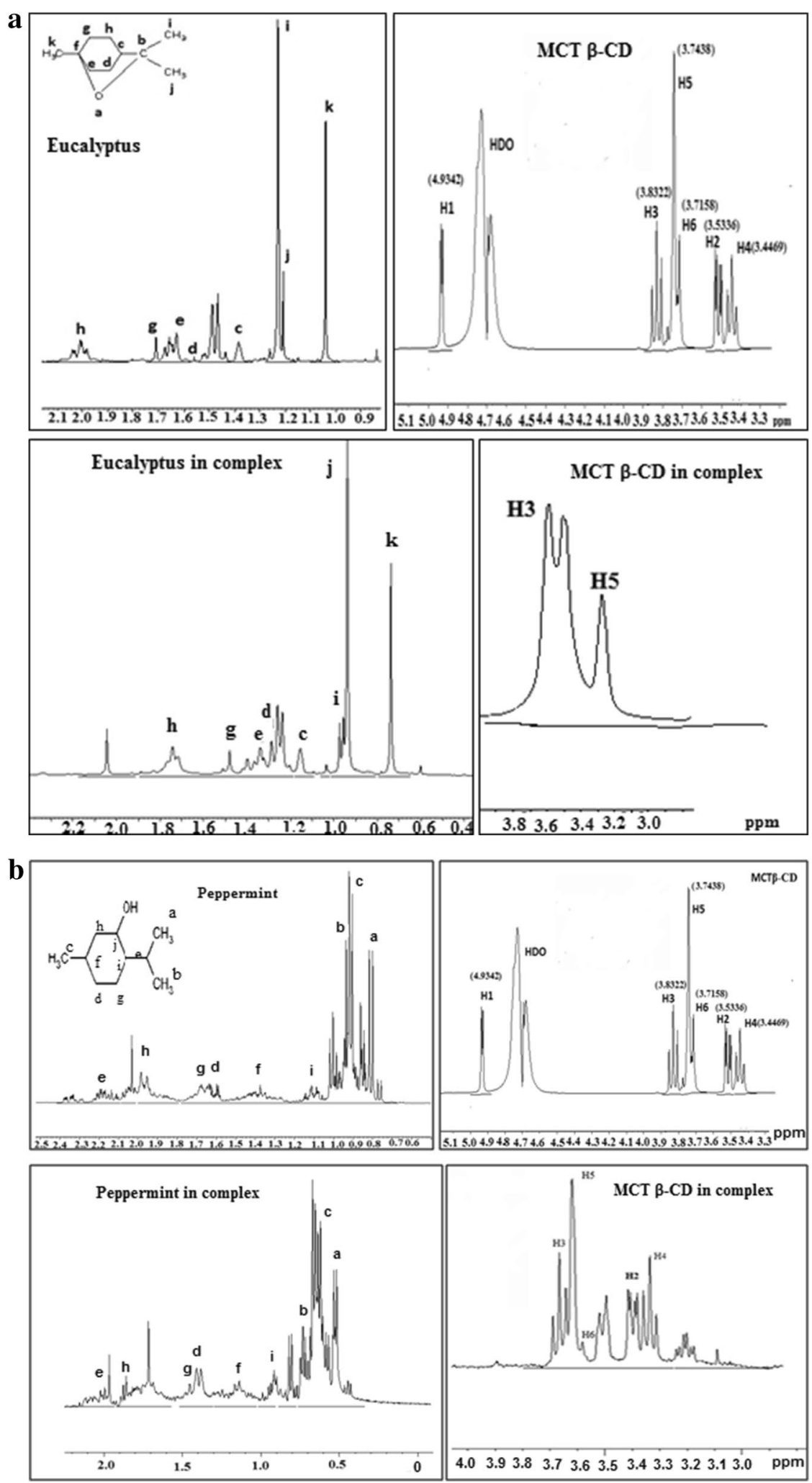

Fig. $8{ }^{1} \mathrm{H}$-NMR spectral analysis of MCT $\beta-C D$ in free and complex state with essential oils in free and complex states. a Eucalyptus b Peppermint 

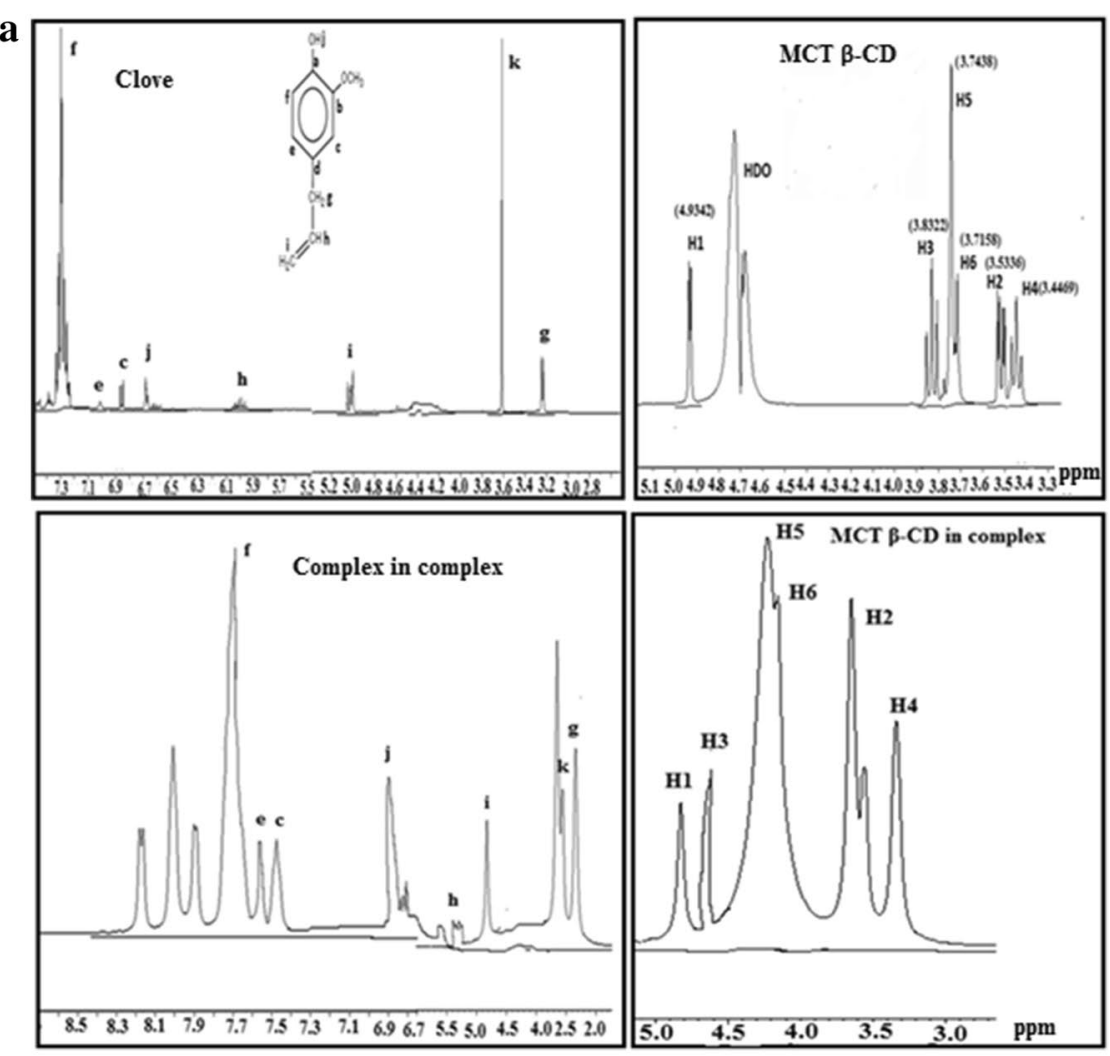

b
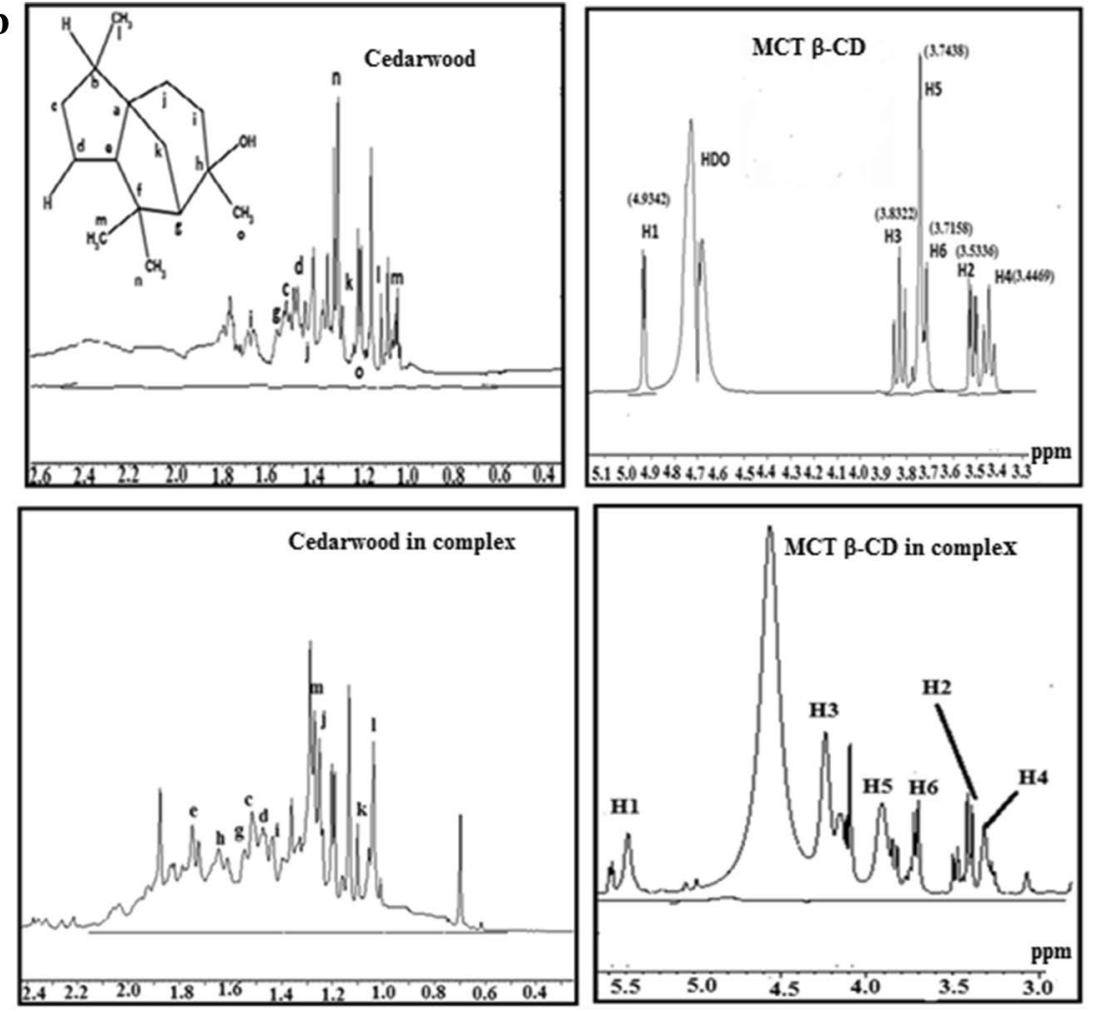

Fig. $9{ }^{1} \mathrm{H}$-NMR spectral analysis of MCT $\beta-C D$ in free and complex state with essential oils in free and complex states. a Clove b Cedarwood 

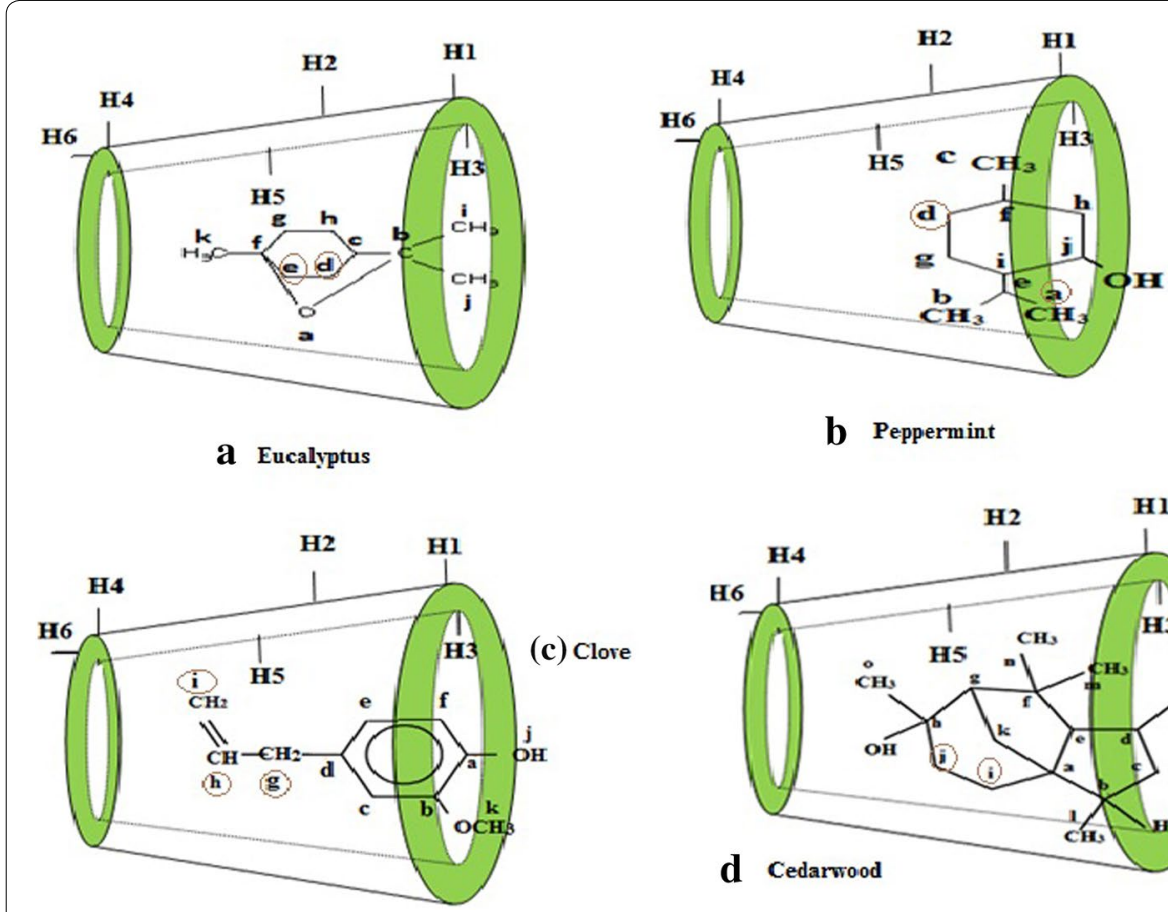

b Peppermint

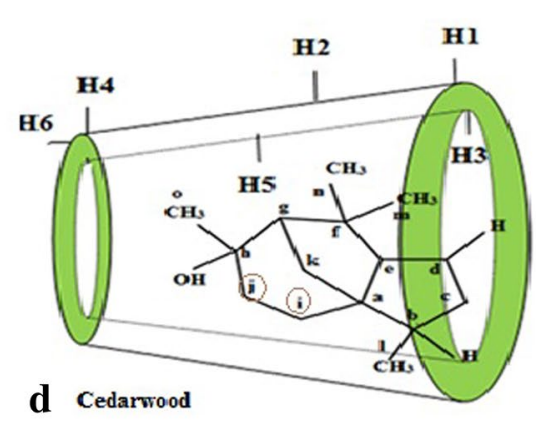

Fig. 10 Inclusion complexation of MCT $\beta-C D$ with oils: a $E O, \mathbf{b} P O, \mathbf{c} C O, \mathbf{d} C d O$ (* encircled protons of oil molecules had the highest induced shifts)

Stability analysis of oils through MCT $\beta$-CD complex-before and after wash

The application of oils on cotton was through the host compound rather than its direct application on cotton, in which, the oils are physically adsorbed on the treated surface in three subsequent phases; surface adsorption, absorption and finally the capillary action of oils into the fibrous pores of cotton that result in the development of vander-waal forces between oils and cotton at low temperature. Oils generally forms multi-molecular layer on the surface of cotton. But, covalent bonded host (MCT $\beta$-CD) tends to trap the oils into its cavities that further depends upon the compatibility between the sizes of guest and host cavity and also the thermodynamic interactions between host, guest and the solvent used (alcohol in the present case) due to the requirement of the structural conformation for either partial or full entrapment of oils into the cavities of host. The oils are hydrophobic (apolar) in nature, so these bind strongly to the hydrophobic cavities of the host. The retention of oils in the host cavities don't comply with the chemical bonding between the host and oils as the formation of inclusion complex do not exert any structural modification of the oils to be chemically bonded to the host or cotton. As if, the oils get chemically bonded to the host cavities, then to release oils on demand would require a lot of activation energy to dismantle oils from the host cavities. Thus, only non-covalent bonds (hydrophobic interactions along with vanderwaal forces) are formed in inclusion complex that allows the oils to be released on its own due to its volatile nature in a controlled manner as there is a dynamic equilibrium between the oils trapped in the host cavity and the water (moisture) present in its surroundings. Thus, all experimented oils fit well into the host cavities and had shown a curtailed release from the cotton. $\mathrm{EO}$ and $\mathrm{CO}$ were the slowest to fade off in the initial hours in comparison to the $\mathrm{PO}$ and $\mathrm{CdO}$, with 

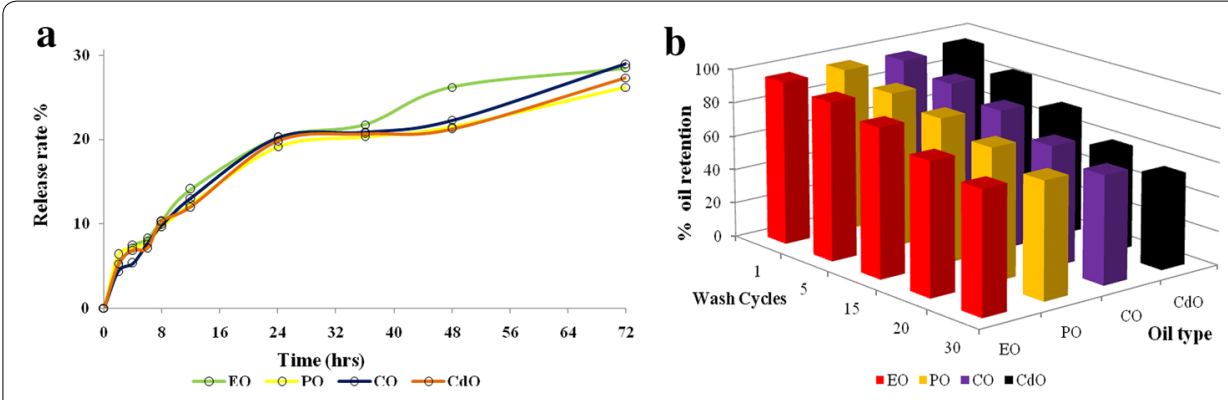

Fig. 11 a \% Release of oils from MCT $\beta$-CD moiety with time; $\mathbf{b} \%$ oil retention on functionalized cotton after 30 wash cycles

EO being the most stable after initial $2 \mathrm{~h}$, whereas, $\mathrm{CO}$ had shown the fastest sublimation (Fig. 11a). After the initial quick release of PO, the oil had shown a moderate release rate after $72 \mathrm{~h}$. This was due to the better settlement of oil in the cyclodextrin cavities after the initial sublimation from the cotton surface during drying. This had facilitated the suppression of oil release from the cotton's surface and thus, prevented their fading off. The eugenol of $\mathrm{CO}$ is the middle note of the oil; on the other hand, cedrol of $\mathrm{CdO}$ behaves as the base note that lasted for longer time span than eugenol. In addition, monoterpenes as eugenol and thyme constitutes $\mathrm{CO}$, whereas, sesquiterpenes as cedrol forms the backbone $\mathrm{CdO}$. Their presence dictates the volatility of oils from cotton as monoterpenes being more volatile than the sesquiterpenes from the oil compositions.

All the oils were retained almost up to $65 \%$ even after 20 vigorous washes and substantial oil \% was still present even after 30 washes. The high \% aroma retention was due to the presence of anchored cavities to hold and control the release of oil from the surface of cotton. $\mathrm{EO}>\mathrm{PO}>\mathrm{CO}>\mathrm{CdO}$ was the observed trend of \% retained oils. $\mathrm{CdO}$ was left in the least proportion on cotton. This might be due to the reason that the retention time of cedarwood was the minimum on cotton that washed off easily after wash cycles as seen in Fig. 11 b.

\section{Conclusions}

The concentration and $\mathrm{pH}$ of $\mathrm{MCT} \beta-\mathrm{CD}$ are the most influencing variables for the treated cotton as increase in concentration and $\mathrm{pH}$ of $\mathrm{MCT} \beta-\mathrm{CD}$ had resulted in an increase in GY\%, but TS\% was tremendous ranging from low strength loss at low $\mathrm{pH}$ values along with some strength improvement at higher concentrations and low $\mathrm{pH}$ index, however, at higher $\mathrm{pH}$, the strength had decreased. With the increase in concentration and temperature together, $\mathrm{N}_{2} \%$ had decreased but $\mathrm{pH}$ played a role in the prevention of the hydrolysis of the chlorotriazine moiety for better fixation onto cotton. The inclusion complex of MCT $\beta-C D$ and oils had suppressed the quicker fading off the oils from the semi-enclosed cavities.

Authors' contributions

AK and JNC planned the work. AK carried out the work and drafted the manuscript. Both authors read and approved the final manuscript.

Competing interests

The authors declare that they have no competing interests. 
Received: 5 June 2016 Accepted: 24 October 2016

Published online: 28 March 2017

\section{References}

Anitha, R., Ramachandran, T., Rajendran, R., \& Mahalakshmi, M. (2011). Microencapsulation of lemon grass oil for mosquito repellent finishes in polyester textiles. Elixir Bio Physics., 40, 5196-5200.

Bendak, A., Allam, O. G., \& El Gabry, L. K. (2010). Treatment of polyamides fabrics with cyclodextrins to improve antimicrobial and thermal stability properties. The Open Textile, Journal, 3, 6-13.

Bereck, A. (2010). Cyclodextrins in textile finishing: Fixation and analysis. Advanced Material Research, 93-94, 1-4.

Bergamasco, R. C., Gisella, M. Z., \& Flavio, F. M. (2007). Grafting of cyclodextrins onto filter paper. Journal of Inclusion Phenomenon and Macrocyclic Chemistry, 57, 75-78.

Bhaskara-Amrit, U. R., Agrawal, P. B., \& Warmoeskerken, M. M. C. G. (2011). Applications of $\beta$-cyclodextrins in textiles. Autex Research Journal, 11(4), 94-101.

Boonsod, T. (2007). Finishing cotton and silk fabric with Glyoxal- $\beta$-cyclodextrin complexes. Thesis: Graduate School, Kasetsart University.

Cabrales, L., Abidi, N., Hammond, A., \& Hamood, A. (2012). Cotton fabric functionalization with cyclodextrins. Journal of Material \& Environmental Sciences, 3(3), 561-574.

Halim, A., El-Newehy, F. A., Abdel-Mohdy, F. A., \& Al-Deyab, S. S. (2010). Chitosan and monochlorotriazinyl-beta-cyclodextrin finishes improve antistatic properties of cotton/polyester blend and polyester fabrics. Carbohydrate Polymers, 82(1), 202-208.

Halim, A. E. S., Fouda, M. M. G., Sanaa, M. El-S, Hamdy, I., \& AI-D, Salem S. (2011). Antimicrobial activity of monochlorotriazinyl- $\beta$-cyclodextrin/chlorohexidin diacetate finished cotton fabrics. Carbohydrate Polymers, 86, 1389-1394

Hauser, P. J., \& Jianshuo, N. (2000). Covalently bound cyclodextrin: a new functional finish for cellulosics. Proceedings of the Annual International Conference \& Exhibition of AATCC, 1, 1-8.

Ibrahim, N. A., Allam, E. A., El-Hossamy, M. B., \& El-Zairy, W. M. (2007). UV-protective finishing of cellulose/wool blended fabrics. Polymer-Plastic Technology and Engineering, 46(9), 905-911.

Khanna, S., Sharma, S., \& Chakraborty, J. N. (2015). Performance assessment of fragrance finished cotton with cyclodextrin assisted anchoring hosts. Fashion \& Textiles. doi:10.1186/s40691-015-0042-9,1-17.

Levya, E., Moctezuma, E., Strouse, J., \& Agaribay, M. A. G. (2001). Spectrometric and 2D NMR Studies on the complexation of chlorophenols with cyclodextrins. Journal of Inclusion Phenomenon and Macrocyclic Chemistry, 39, 41-46.

Marwa, A. A., Amr, A., Abou-Okeil, A., \& Nermin, M. A. (2013). Comfort properties of the inner padding layer for motorcycle helmet. Life Sciences Journal, 10(4), 1386-1399.

Medronho, B., Andrade, R., Vivod, V., Ostlund, A., Miguel, M. G., Lindman, B., et al. (2012). Cyclodextrin-grafted cellulose: Physico-chemical characterization. Carbohydrate Polymers, 30, 1-7.

Moldenhauer, J. P. \& Reuscher, H. (1999). Textile finishing with MCT- $\beta$-cyclodextrin. In J. J. Torres Labandeira, J. L. Vila-Jato (Eds.), Proceedings of the 9th International Symposium on Cyclodextrins (pp. 161-165). Dordrecht: Kluwer Academic Publishers.

Nelson, G. (2002). Application of microencapsulation in textiles. International Journal of Pharmaceutics, 242, 55-62.

Peila, G. R., Migliavacca, F. A., \& Sicardi, A. F. S. (2012). A comparison of analytical methods for the quantification of a reactive $\beta$-cyclodextrin fixed onto cotton yarns. Cellulose, 19, 1097-1105.

Pessine, F. B. T., Calderini, A. \& Alexandrino, G. L. (2012). Review: Cyclodextrin Inclusion Complexes Probed by NMR Techniques. Magnetic Resonance Spectroscopy, Prof. Dong-Hyun Kim (Ed.), ISBN: 978-953-51-0065-2, InTech, Available from: http://www.intechopen.com/books/magneticresonance-spectroscopy/review-study-of-inclusion-complexeswith-cyclodextrins-by-mrs. pp. 237-264.

Popescu, V., Muresan, E. I., \& Grigoriu, Ana-M. (2011). Monochlorotriazinyl- $\beta$-cyclodextrin grafting onto polyester fabrics and films. Carbohydrate Polymers, 86, 600-611.

Rehmann, L., Yoshii, H., \& Furuta, T. (2003). Characteristics of modified $\beta$-cyclodextrin bound to cellulose powder. Starch/ Stärke, 55(1), 313-318.

Shahba, F. A. (2008). Production and characterization of novel perfumed curtain fabrics. Research Journal of Textiles \& Apparels, 12(4), 31-40

Shown, I., \& Murthy, C. N. (2008). Grafting of cotton fiber by water-soluble cyclodextrin-based polymer. Journal of Applied Polymer Science, 111(4), 2056-2061.

Sricharussin, W., Sopajaree, C., Maneerung, T., \& Sangsuriya, N. (2009). Modification of cotton fabrics with $\beta$-cyclodextrin derivative for aroma finishing. Journal of Textile Institute, 100(8), 682-687.

Wen, J., Liu, B., Yuan, E., Ma, Y., \& Zhu, Y. (2010). Preparation and physicochemical properties of the complex of naringenin with hydroxypropyl- $\beta$-cyclodextrin. Molecules, 15, 4401-4407. 